\title{
Cannabinoid Receptor Type 1 Expression in the Developing Avian Retina: Morphological and Functional Correlation With the Dopaminergic System
}

\begin{abstract}
Luzia da Silva Sampaio ${ }^{1}$, Regina C. C. Kubrusly ${ }^{2}$, Yolanda P. Colli ${ }^{1}$, Priscila P. Trindade ${ }^{1}$, Victor T. Ribeiro-Resende ${ }^{1}$, Marcelo Einicker-Lamas ${ }^{3}$, Roberto Paes-de-Carvalho ${ }^{4}$, Patricia F. Gardino ${ }^{1}$, Fernando G. de Mello ${ }^{1}$ and Ricardo A. De Melo Reis ${ }^{1 *}$

'Laboratório de Neuroquímica, Instituto de Biofísica Carlos Chagas Filho, Universidade Federal do Rio de Janeiro, Rio de Janeiro, Brazil, ${ }^{2}$ Laboratório de Neurofarmacologia, Instituto Biomédico, Universidade Federal Fluminense, Niterói, Brazil, ${ }^{3}$ Laboratório de Biomembranas, Instituto de Biofísica Carlos Chagas Filho, Universidade Federal do Rio de Janeiro, Rio de Janeiro, Brazil, ${ }^{4}$ Laboratório de Neurobiologia Celular, Programa de Neurociências, Universidade Federal Fluminense, Niterói, Brazil
\end{abstract}

OPEN ACCESS

Edited by:

Fabricio A. Pamplona Entourage Phytolab, Brazil

Reviewed by: Victoria P. Connaughton, American University, United States Eric Murillo-Rodriguez, Anahuac Mayab University, Mexico

*Correspondence: Ricardo A. De Melo Reis ramreis@biof.ufrj.br

Received: 15 December 2017 Accepted: 19 February 2018

Published: 12 March 2018

Citation:

da Silva Sampaio L, Kubrusly RCC, Colli YP, Trindade PP,

Ribeiro-Resende VT,

Einicker-Lamas M,

Paes-de-Carvalho R, Gardino PF, de Mello FG and De Melo Reis RA

(2018) Cannabinoid Receptor

Type 1 Expression in the Developing

Avian Retina: Morphological and Functional Correlation With the

Dopaminergic System.

Front. Cell. Neurosci. 12:58.

doi: 10.3389/fncel.2018.00058
The avian retina has been used as a model to study signaling by different neuro- and gliotransmitters. It is unclear how dopaminergic and cannabinoid systems are related in the retina. Here we studied the expression of type 1 and 2 cannabinoid receptors $\left(\mathrm{CB}_{1}\right.$ and $\left.\mathrm{CB}_{2}\right)$, as well as monoacylglycerol lipase (MAGL), the enzyme that degrades 2-arachidonoylglycerol (2-AG), during retina development. Our data show that $\mathrm{CB}_{1}$ receptor is highly expressed from embryonic day 5 (E5) until post hatched day 7 (PE7), decreasing its levels throughout development. $\mathrm{CB}_{1}$ is densely found in the ganglion cell layer (GCL) and inner plexiform layer (IPL). $\mathrm{CB}_{2}$ receptor was also found from E5 until PE7 with a decrease in its contents from $E 9$ afterwards. $\mathrm{CB}_{2}$ was mainly present in the lamination of the IPL at PE7. MAGL is expressed in all retinal layers, mainly in the IPL and OPL from E9 to PE7 retina. $\mathrm{CB}_{1}$ and $\mathrm{CB}_{2}$ were found both in neurons and glia cells, but MAGL was only expressed in Müller glia. Older retinas (PE7) show $\mathrm{CB}_{1}$ positive cells mainly in the INL and co-expression of $\mathrm{CB}_{1}$ and tyrosine hydroxylase $(\mathrm{TH})$ are shown in a few cells when both systems are mature. $\mathrm{CB}_{1}$ co-localized with $\mathrm{TH}$ and was heavily associated to $D_{1}$ receptor labeling in primary cell cultures. Finally, cyclic AMP (cAMP) was activated by the selective $D_{1}$ agonist SKF38393, and inhibited when cultures were treated with WIN55, 212-2 (WIN) in a CB $_{1}$ dependent manner. The results suggest a correlation between the endocannabinoid and dopaminergic systems (DSs) during the avian retina development. Activation of $\mathrm{CB}_{1}$ limits $\mathrm{CAMP}$ accumulation via $D_{1}$ receptor activation and may influence embryological parameters during avian retina differentiation. 


\section{INTRODUCTION}

The retina is a unique tissue located in the posterior part of the eye involved with light transduction in visual information. The vertebrate retina, easily accessible to experimental manipulation, formed by seven major cell types, reviewed in Masland (2012), is extensively used as an experimental model to investigate cell interactions. Neurons and glia cells interact bidirectionally, and the avian retina has been used in the last 40 years, as a model to study the role of neuro-glia interactions in cell migration and development (Reis et al., 2007; de Melo Reis et al., 2008).

Dopamine is the main catecholamine found in a subtype of retinal amacrine cells located in the inner nuclear layer (INL; Reis et al., 2007). Emergence of amacrine cells begins at early stages (around embryonic day 3, E3) and is concluded at E9 (Prada et al., 1991; Calaza Kda and Gardino, 2010). Tyrosine hydroxylase $(\mathrm{TH})$ expression is only found around E12, while $D_{1} / D_{5}$ type dopaminergic receptors coupled to cyclic AMP (cAMP) production are fully functional on E7 (de Mello, 1978) as compared to the end of the proliferation period (Gardino et al., 1993). Indeed, analysis of chick retina sections show $\mathrm{TH}$ positive dopaminergic amacrine cells located in the dorsal retina at E13/E14, and beginning to be defined at E16, with a rising arborization complexity until hatching, in a way that at E18/2 days post hatching dopaminergic cells are uniformly distributed throughout the retina (Gardino et al., 1993). In addition, specific dopaminergic amacrine cell subpopulation shows a more restrict neurogenesis period than the general amacrine cell population. However, dopaminergic system (DS) development only becomes complete in the post-embryonic phase, when $\mathrm{TH}$ expressing in amacrine cells in the INL are found in a highly connected wiring pattern with retinal ganglion cells, located in the ganglion cell layer (GCL), exerting a major inhibitory input. TH expression is modulated and dependent on several extrinsic and intrinsic factors that determine the dopaminergic phenotype, such as the cAMP signaling cascade activated by PACAP (Reis et al., 2007; Fleming et al., 2013). However, a clear picture of dopaminergic amacrine cell development is still not completely understood.

The endocannabinoid system (ECS) is present in almost all classes of vertebrates (Cottone et al., 2013). The modulation of cannabinoid activity is mediated by selective type- 1 and type- 2 cannabinoid receptors $\left(\mathrm{CB}_{1}\right.$ and $\left.\mathrm{CB}_{2}\right)$, which are members of the $\mathrm{G}$ protein-coupled receptor (GPCR) family that inhibit adenylate cyclase leading to a decrease in cAMP levels. Specific endogenous endocannabinoids agonists drive these receptors. These bioactive lipids, such as anandamide (AEA) and 2-arachidonoylglycerol (2-AG), are synthesized and degraded by a limited group of enzymes presented in different cell types (Howlett, 2002). One of these enzymes, monoacylglycerol lipase (MAGL), is a serine hydrolase involved in the metabolism of 2-AG in the brain (Chanda et al., 2010).

In the $\mathrm{CNS}, \mathrm{CB}_{1}$ are found mainly in presynaptic neurons, functioning as a regulatory mechanism for the release of both excitatory and inhibitory neurotransmitters (Katona and Freund, 2008).
The ECS is expressed at very early stages of the avian retinal development, as evidenced by $\mathrm{CB}_{1}$ expression in neurons (Leonelli et al., 2005). Recently, $\mathrm{CB}_{2}$ has been described in Müller glia in mammals (Bouskila et al., 2013). Straiker et al. (1999) showed for the first time that $\mathrm{CB}_{1}$ is expressed in the avian retina in two synaptic retinal layers, the inner plexiform and outer plexiform layers (IPL and OPL, respectively). $\mathrm{CB}_{1}$ expression was also reported in some amacrine and ganglion cell bodies and axons (Straiker et al., 1999). We recently showed that $\mathrm{CB}_{1}$ and $\mathrm{CB}_{2}$ receptors are found in both neurons and glial avian retinal cells in culture. These receptors regulate avian retina signaling (GABA release, calcium mobilization and cAMP levels) at critical embryonic stages during synapse formation (Kubrusly et al., 2018).

Dopaminergic neurons are modulated by ECS in different areas of the CNS. $\mathrm{CB}_{1}$ and endocannabinoids are abundant in the DS, acting to modulate dopamine release. It has been reported that selective and non-selective $\mathrm{CB}_{1}$ agonists decrease the dopamine release in the guinea-pig retina (Schlicker et al., 1996). However, the relationship between dopaminergic and ECSs during retinal development is still unclear. Therefore, we characterized the expression of $\mathrm{CB}_{1}$ and $\mathrm{CB}_{2}$ receptor, and also MAGL, during the development of avian retina as well as the possible functional correlation between the dopaminergic and ECSs in this process.

\section{MATERIALS AND METHODS}

All materials used were of analytical grade. Dulbecco's Modified Eagle Medium: Nutrient Mixture F-12 (DMEM/F-12), fetal calf serum (FCS) and gentamycin were obtained from Gibco (USA).

\section{Animals}

All experiments involving animals were approved by and carried out in accordance with the guidelines of the Institutional Animal Care and Use Committee of the Federal University of Rio de Janeiro (permit number IBCCF-035), and experimental procedures were carried out in accordance with the guidelines of the Brazilian Society of Neuroscience and Behavior (SBNeC). Fertilized White Leghorn eggs (Gallus gallus) were obtained from a local hatchery and kept in an appropriate incubator under $12 \mathrm{~h}$ light and $12 \mathrm{~h}$ dark cycles until the day of use. The eyes from chick embryos ranging from 5, 7, 9 and 14 days of incubation to 7 days post-hatching stage were used in this study. We started with embryonic day 5 (E5) since amacrine cells begin to differentiate early (E3; Calaza $\mathrm{Kda}$ and Gardino, 2010), $\mathrm{CB}_{1}$ receptors are found around E5 (Leonelli et al., 2005), and the first dopaminergic marker is described around E6 (dopamine transporter, DAT, Kubrusly et al., 2003). $D_{1}$ receptors are found around E7 (de Mello, 1978), and amacrine neurons end their migration process (Gardino et al., 1993). A peak on retinal synaptogenesis is found around E14 (Calaza Kda and Gardino, 2010). And at P7, DS in the retina is fully differentiated (Gardino et al., 1993). 


\section{Preparation of Tissue and Retinal Radial Sections}

After decapitation, the embryos and chicks eyes were enucleated and fixed for $2 \mathrm{~h}$ in $4 \%$ paraformaldehyde in phosphate buffer $0.16 \mathrm{M}, \mathrm{pH} 7.4(\mathrm{~PB})$; after these procedures, the eyes were washed in $\mathrm{PB}$ three times. In $24 \mathrm{~h}$, the eyes were cryoprotected in sucrose $15 \%$ and $30 \%$, embedded in medium optimal cutting temperature (O.C.T. compound, Sakura Finetek, Torrance, CA, USA), frozen and then cut perpendicularly to the vitreal surface on a Leica CM3050 S cryostat $(12 \mu \mathrm{m})$.

\section{Mixed Retinal Cells in Culture}

Primary cell cultures of chick retinal cells at stage E8 (8-days embryo) were prepared as described (Paes de Carvalho and de Mello, 1982). Briefly, retinas were dissected on a $\mathrm{Ca}^{2+}$. and $\mathrm{Mg}^{2+}$-free salt balanced medium (CMF) and cleared of the pigmented epithelium. The retinas were dissociated using TrypLE $^{\circledR}$ (Thermo Fisher Scientific) and incubated at $37^{\circ} \mathrm{C}$ for $10 \mathrm{~min}$. After brief centrifugation, the pellet was suspended in $1 \mathrm{ml}$ of DMEM/F-12 medium supplemented with 10\% FCS and mechanically dissociated with a Pasteur pipette. Cells were plated on $13 \mathrm{~mm}$ coverslips (Marienbad, German; $1.6 \times 10^{6}$ cells), or $33.7 \mathrm{~mm}$ plates (TPP, Trasadingen, Switzerland; $20 \times 10^{6}$ cells), previously coated with Poly-L-Lysine. The cultures were maintained in an incubator at $37^{\circ} \mathrm{C}$ under $5 \% \mathrm{CO}_{2}$ atmosphere for 6 days (E8C6 cells in culture). E8C6 on $13 \mathrm{~mm}$ coverslips were fixed for $15 \mathrm{~min}$ in $4 \%$ paraformaldehyde in PBS.

\section{Immunofluorescence}

Retina sections and primary cell cultures of retinal cells were washed three times with PBS and incubated for $30 \mathrm{~min}$ with $0.15 \%$ Triton X-100 and 3\% FCS in PBS. This buffer was removed and the primary antibodies of interest added in an overnight incubation at $4^{\circ} \mathrm{C}$. The sections and cultures were washed with PBS and incubated with fluorochrome-conjugated secondary antibody for $2 \mathrm{~h}$ at room temperature protecting from the light. After rinsing with PBS, the retinas and cultures were mounted using a PBS containing $40 \%$ glycerol and DAPI $0.04 \mu \mathrm{g} / \mathrm{ml}$ solution and were examined in a Zeiss Axio Imager 2 Fluorescence Microscope with Apotome and/or confocal microscope (LSM 510 Meta, Zeiss, Germany).

For the immunofluorescence results, specific antibodies were used according to the recommendation of each manufacturer. For primary antibodies, anti-CB1 (anti-cannabinoid receptor 1 produced in goat-SAB2500190 from SigmaAldrich), dilution of 1:100; anti-CB2 (CB2 antibody (M-15) produced in goat-sc-10076 from Santa Cruz Biotechnology) dilution of 1:100; anti-MAGL (anti-MAGL produced in rabbit-ab152002 from abcam) dilution of 1:100; anti-TH (antityrosine hydroxylase produced in rabbit-AB152 from EMD Millipore) dilution of 1:100; anti-MAP2 (anti-MAP2 produced in mouse-ab11267 from abcam) dilution of 1:400; anti-2M6 (monoclonal anti-2M6 (kindly provided by Dr. B. Schlosshauer; Max-Planck-Institute, Tübingen, Germany, Schlosshauer et al., 1991)), dilution of 1:400; anti- $\mathrm{D}_{1}$ (anti-dopamine $\mathrm{D}_{1 \mathrm{R}}$ produced in rabbit-NBP2-16213 from Novusbio) dilution of 1:100.
For secondary antibodies, Alexa Fluor ${ }^{\circledR} 488$ donkey anti-goat (A11055 produced from Thermo Fisher Scientific); Alexa Fluor ${ }^{\circledR} 488$ donkey anti-rabbit (A21206 produced from Thermo Fisher Scientific); Alexa Fluor ${ }^{\circledR} 594$ donkey anti-rabbit (A21207 produced from Thermo Fisher Scientific); Alexa Fluor ${ }^{\circledR}$ 594 donkey anti-mouse (A21203 produced from Thermo Fisher Scientific), all were used at the 1:500 dilution.

\section{Western Blotting}

Fresh retinas from embryos and chicks, and E8C6 cells culture were washed twice with PBS, homogenized with a lysis buffer (EDTA $10 \mathrm{mM}$, HEPES-Tris $50 \mathrm{mM}$, Sucrose $1 \mathrm{M}$, trypsin inhibitor $0.15 \mathrm{mg} / \mathrm{ml}$ ) and the total protein concentration was quantified (Lowry et al., 1951). Total proteins were separated by polyacrylamide gel electrophoresis (10\% SDSPAGE) and transferred to nitrocellulose membranes (Laemmli, 1970). After $1 \mathrm{~h}$ in blocking buffer (5\% low fat dried milk in Tris-buffered saline-TBS), the immunodetection was performed by incubating the membrane with a specific primary antibody overnight at $4^{\circ} \mathrm{C}$. The membranes were washed with TBS and incubated with secondary horseradish peroxidase (HRP)-conjugated antibody for $2 \mathrm{~h}$ at room temperature. The proteins of interest were finally detected using Luminata ${ }^{\mathrm{TM}}$ Forte (Merck Millipore) and ChemiDoc MP system (Bio-Rad).

For the western blotting results, we used specific antibodies, according to the recommendation of each manufacturer. For primary antibodies, anti- $\mathrm{CB}_{1}$ (anti-cannabinoid receptor $\mathrm{CB}_{1}$ (1-77) produced in rabbit-209550 from Calbiochem) was used at a dilution of 1:1000; anti- $\mathrm{CB}_{2}$ (anti-CNR2 antibody produced in mouse-WH0001269M1 from Sigma-Aldrich) was used at a dilution of 1:1000; anti-TH (anti-tyrosine hydroxylase produced in rabbit-AB152 from EMD Millipore) was used at a dilution of 1:500; anti- $\mathrm{D}_{1}$ (anti-dopamine $\mathrm{D}_{1 \mathrm{R}}$ produced in rabbit-NBP2-16213 from Novusbio) was used at a dilution of 1:500; anti-DARP32 (anti-DARPP-32 antibody [EP720Y] produced in rabbit-ab40801 from abcam) was used at a dilution of 1:500; anti-Nurr-1 (anti-Nurr-1 antibody produced in rabbit-ab93332 from abcam) was used at a dilution of 1:500; anti-ERK1/2 (anti p44/42 MAPK (Erk1/2) antibody produced in mouse-4696 from cell signaling) was used at a dilution of 1:1000; anti- $\beta$ actin (anti- $\beta$-actin clone AC-15 produced in mouse-A5441 from Sigma-Aldrich) was used at a dilution of 1:5000. For secondary antibodies, HRP-conjugated goat anti-mouse (A5278 from Sigma-Aldrich) and HRP-conjugated goat anti-rabbit (A0545 from Sigma-Aldrich) were used at a dilution of 1:5000 (for the $\beta$ actin protocol, we used the dilution $1: 25,000)$. For statistical analysis, densitometry for each protein of interest was performed using Scion Image software followed by ANOVA.

\section{cAMP Accumulation}

Accumulation of cAMP was assayed according to the competitive binding assay as described previously (Kubrusly et al., 2005). Mixed retinal cells were washed with PBS and pre-treated with $5 \times 10^{-4} \mathrm{M}$ IBMX, an inhibitor of phosphodiesterases, for $15 \mathrm{~min}$ in $1 \mathrm{ml}$ of DMEM/F-12 plus $20 \mathrm{mM}$ HEPES pH 7.4 at $37^{\circ} \mathrm{C}$. To measure adenylyl cyclase activity, we used $5 \times 10^{-5} \mathrm{M}$ SKF38393, 


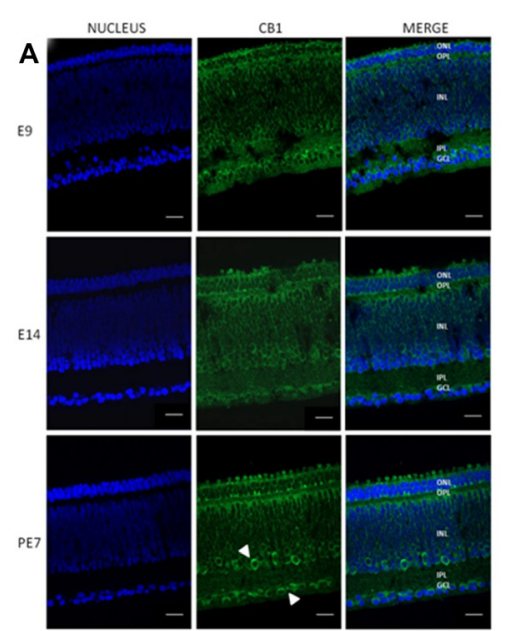

B
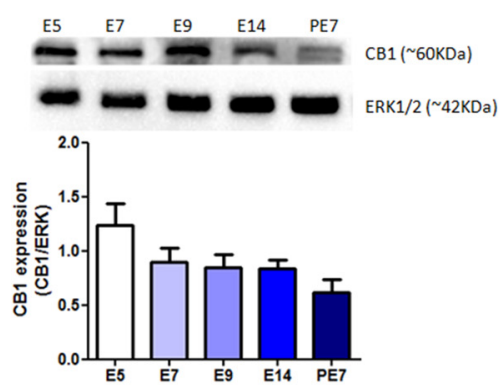
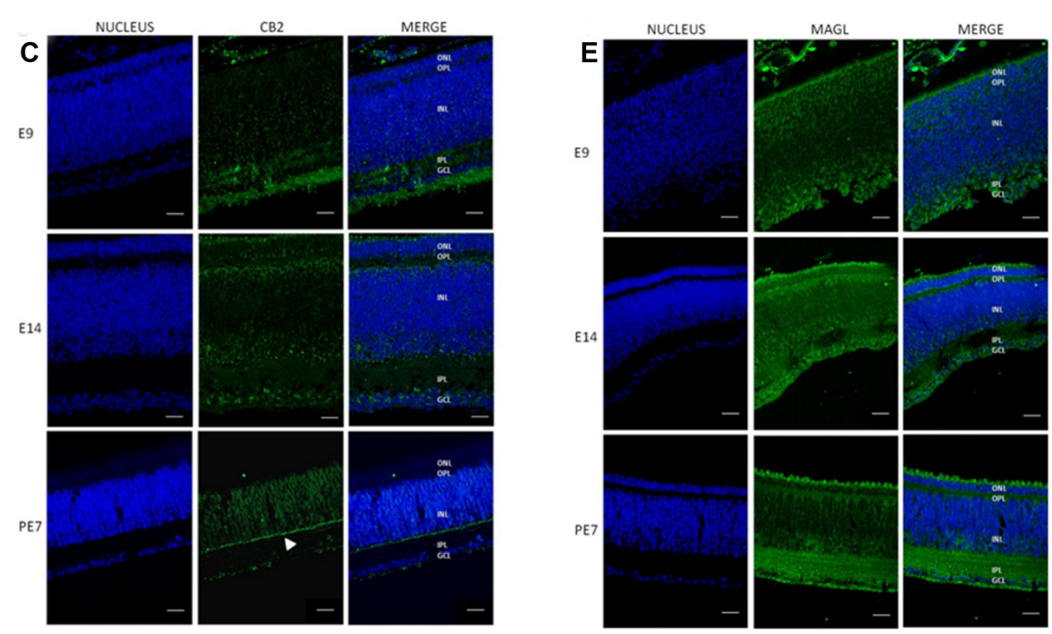

D

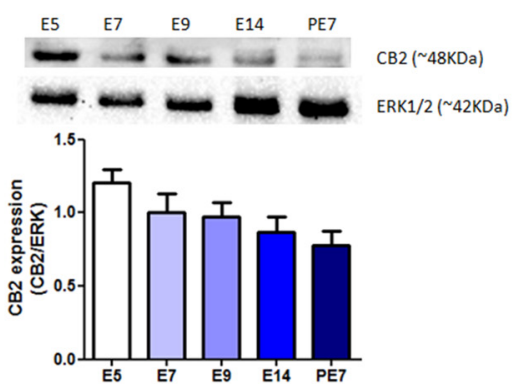

FIGURE 1 | Expression of selective endocannabinoid markers during avian retina development. Expression of $\mathrm{CB}_{1}$, $\mathrm{CB}_{2}$ and monoacylglycerol lipase (MAGL) using immunofluorescence and western blotting. In (A), expression of $\mathrm{CB}_{1}$ (green) at embryonic stages E9 and E14 and post-hatched 7 days (PE7) in chick retina. At PE7, $\mathrm{CB}_{1}$ is mainly found in cells of the inner nuclear layer (INL) and ganglion cell layer (GCL; white arrows). (B) Western blot highlights CB 1 expression from embryonic day 5 (E5) to PE7. Expression of ERK 1/2 was used as loading control. In (C), CB 2 (green) expression from E9 to PE7 primarily in the inner plexiform layer (IPL) lamina (white arrow). $\mathrm{CB}_{2}$ expression from E5, as shown in (D). In (E), MAGL expression (green) from E9 to PE7 is shown, its distribution is evident across all layers of the retina. Scale bar of $20 \mu \mathrm{m}$, all images were obtained with $40 \times$ magnification in a Zeiss fluorescence microscope. $N=6$ for each analysis.

a $\mathrm{D}_{1 \mathrm{R}}$ agonist, for $30 \mathrm{~min}$ at $37^{\circ} \mathrm{C}$, or $1 \times 10^{-7} \mathrm{M}$ forskolin, a general activator for this enzyme. The treatments performed were $10^{-6} \mathrm{M}$ AM251, a $\mathrm{CB}_{1}$ antagonist, for $15 \mathrm{~min} ; 10^{-6} \mathrm{M}$ WIN55, 212-2, a non-selective cannabinoid receptor agonist, for $30 \mathrm{~min}$. The reaction was stopped by addition of $100 \mu \mathrm{l}$ trichloroacetic acid $100 \%$ ( $5 \%$ final) acid followed by storage at $-20^{\circ} \mathrm{C}$ for $24 \mathrm{~h}$. After centrifugation (1000 $\mathrm{g}$ for $10 \mathrm{~min}$ ), the supernatant was passed through an ion-exchange resin column (Dowex 50) to remove the trichloroacetic acid and other nucleotides. The samples containing cAMP were then incubated in the presence of the regulatory subunit of PKA and a fixed trace amount of $\left[{ }^{3} \mathrm{H}\right]$ cAMP in $50 \mathrm{mM}$ acetate buffer, $\mathrm{pH} 4.0$, at $4^{\circ} \mathrm{C}$ for $90 \mathrm{~min}$. The reaction was interrupted by the addition of $200 \mathrm{mM}$ phosphate buffer at $\mathrm{pH}$ 6.0. The samples were filtered through Millipore filters and the radioactivity determined in a Tri Carb 2810 TR Perkin Elmer liquid scintillation analyzer.

\section{Statistical Analysis}

All the results are shown as means \pm SEM. Graphpad Prism $5^{\circledR}$ software was used to analyze the results by one way ANOVA, followed by Tukey post-test. For all the results, $p<0.05$ was taken as the significance level, and the number of experiments is described in each figure legend.

\section{RESULTS}

Our results confirm that $\mathrm{CB}_{1}$ receptor is highly expressed in the chick retina. Indeed, we analyzed its expression during ontogenesis from embryonic day 9 (E9) for immunofluorescence and E5 for western blotting, until post-hatched day 7 (PE7; Figures 1A,B). Western blotting data show a decrease, but not statistically different, in the $\mathrm{CB}_{1}$ expression during avian retinal development (Figure 1B). $\mathrm{CB}_{1}$ is located in almost all retinal layers from E14 to PE7, and is more densely present in the GCL and IPL (Figure 1A).

We also evaluated the expression of other ECS proteins, such as $\mathrm{CB}_{2}$ receptor and MAGL, the enzyme that degrades the endocannabinoid agonist 2-AG. Our data clearly show the expression of $\mathrm{CB}_{2}$ receptor throughout development, between E5 and PE7 retinas (Figure 1D). We also observed a decrease in $\mathrm{CB}_{2}$ protein content from E5 afterwards and that these receptors are mainly present in the lamination of the IPL at PE7 retinas 
(Figure 1C). MAGL is expressed in all retinal layers, but more clearly in the IPL and OPL from E9 to PE7 retina (Figure 1E).

To test our hypothesis of a link between the ECS and the DS, we asked whether the $\mathrm{CB}_{1}$ receptor is co-expressed with $\mathrm{TH}$ in retina dopaminergic cells. We performed western blotting for $\mathrm{TH}$ at different stages, confirming that $\mathrm{TH}$ is highly expressed at PE7 (Figure 2A). TH amacrine neurons express $\mathrm{CB}_{1}$ receptor in the INL and GCL cells around PE7 (Figure 2B). Indeed, $\mathrm{CB}_{1}$ positive cells mainly in the INL are found co-expressed with a few TH positive cells (Figure 2B).

Since dopaminergic neurons express $\mathrm{CB}_{1}$ receptor, we decided to investigate whether this receptor modulate dopaminergic functions in the avian retina. For this purpose, we used primary cell cultures of mixed neurons and Müller glia (Figure 3), as these cells express both $\mathrm{CB}_{1}$ and $\mathrm{CB}_{2}$ receptors (Kubrusly et al., 2018) and also MAGL. $\mathrm{CB}_{1}$ and $\mathrm{CB}_{2}$ are found both in neurons and glia cells, but MAGL is only expressed in Müller glia. $\mathrm{CB}_{1}$ is highly expressed in neuron bodies (Figure 3), and in Müller cells purified culture (Figure 3C).

$\mathrm{CB}_{1}$ was also found to be co-localized with $\mathrm{TH}$ and heavily associated with $D_{1}$ receptor labeling in primary cell cultures (Figures 4A,B). To explore the presence of selective dopaminergic markers in mixed retinal cell cultures, we performed western blot analysis of different proteins associated with the DS. Data revealed the clear expression of the nuclear receptor related 1 protein (Nurr1), $D_{1}$ receptor and dopamineand cAMP-regulated phosphoprotein 32 (Darpp32; Figure 4C) in addition to $\mathrm{CB}_{1}$.

Next, E8C6 cultures were exposed to SKF38393 (SKF), a selective $D_{1}$ agonist, which was able to increase the cAMP levels when compared to controls. Our results show that the cAMP accumulation induced by SKF is lost when cultures were pretreated with WIN55, 212-2 (WIN), a non-selective CB agonist (Figure 5). When cultures were pre-treated with $\mathrm{AM} 251$, a $\mathrm{CB}_{1}$ selective antagonist, and then co-exposed to SKF+WIN, the SKF response was restored (Figure 5), indicating that the repressive effect of WIN on SKF promoted cAMP accumulation was due, mainly, to activation of $\mathrm{CB}_{1}$ receptors.

\section{DISCUSSION}

Here we show the expression of $\mathrm{CB}_{1}$ receptors in the avian retina throughout development, being detected since an early embryonic stage (E5) up to a more mature period (PE7). Moreover, we show a decrease in $\mathrm{CB}_{1}$ protein content during development, but no significance was reached upon ANOVA. $\mathrm{CB}_{1}$ is mainly located in ganglion as well as amacrine cells, present in the GCL and in the INL, respectively. Our work confirms previous studies that have shown the presence of CBs and endocannabinoids metabolic enzymes in the retina of several species such as goldfish, rat, mouse, chick and monkey (Schwitzer et al., 2016). Some of these previous data have shown $\mathrm{CB}_{1}$ expression in ganglion, horizontal and amacrine cells, cone pedicles and rod spherules of photoreceptors (Zabouri et al., 2011a). Leonelli et al. (2005) showed for the first time that, in avian retina, $\mathrm{CB}_{1}$ emerges in $\mathrm{E} 4$, in ganglion cells, while at E18 $\mathrm{CB}_{1}$ is expressed in neurons located in the GCL and INL.

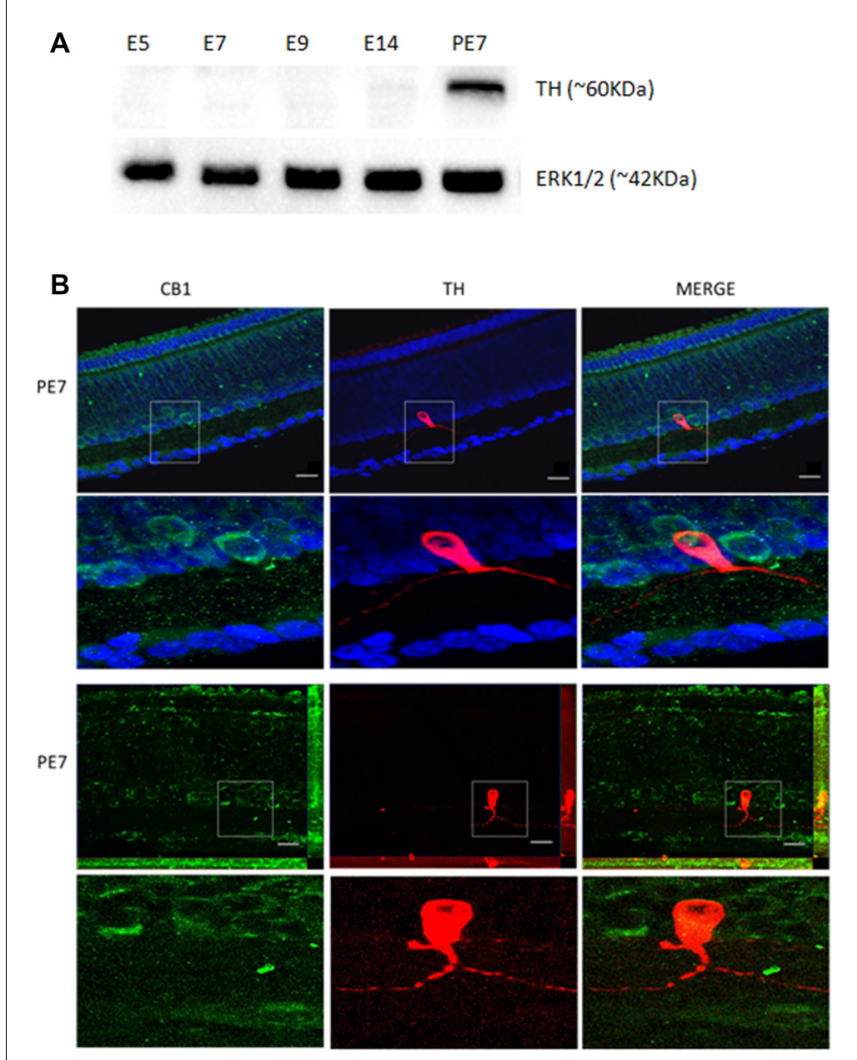

FIGURE 2 | Co-localization of $\mathrm{CB}_{1}$ receptor and tyrosine hydroxylase (TH) enzyme in the avian retina. We evaluated whether dopaminergic neurons, $\mathrm{TH}$ positive cells (red) express $\mathrm{CB}_{1}$ receptor (green) by immunofluorescence. In (A), western blotting for $\mathrm{TH}$ at different stages, confirming that $\mathrm{TH}$ is highly expressed at PE7. ERK1/2 is shown as the loading control. In (B), $\mathrm{CB}_{1}$ and $\mathrm{TH}$ co-expression in PE7 avian retina. As shown, a discrete $\mathrm{TH}$ co-expression with $\mathrm{CB}_{1}$ that is mainly present in neighboring cells in the INL. ApoTome images in upper row and confocal images in lower row. Scale bar of $20 \mu \mathrm{m}$, all images were obtained with $40 \times$ magnification. $N=5$ for each analysis.

We recently showed that $\mathrm{CB}_{1}$ and $\mathrm{CB}_{2}$ receptors are found in both retinal neurons and Müller glia of chick embryos. We found that WIN decreases cAMP production in retinal cells in basal conditions, decreases the number of glial cells that increased $\mathrm{Ca}^{2+}$ evoked by ATP, and inhibited $\left[{ }^{3} \mathrm{H}\right]-\mathrm{GABA}$ release induced by $\mathrm{KCl}$ or L-Aspartate (Kubrusly et al., 2018). Now we evaluated the expression of $\mathrm{CB}_{1}, \mathrm{CB}_{2}$ receptor and MAGL enzyme in the developing retina. $\mathrm{CB}_{2}$ has been reported in rat, mouse and monkey but not in avian retina. $\mathrm{CB}_{2}$ has been shown to be expressed in photoreceptors, horizontal, amacrine and ganglion cells and also in fibers in the INL in adult rat retina (López et al., 2011). Interestingly, $\mathrm{CB}_{2}$ expression appears in Müller cells in the monkey retina (Bouskila et al., 2013). However, there is no information regarding $\mathrm{CB}_{2}$ expression during development of the avian retina. Our data show that $\mathrm{CB}_{2}$ is expressed beginning at E5 and is clearly observed in the lamination of the IPL between E14 and PE7 (Figure 1C). In early retinogenesis, up to E5, retinal cells are essentially in the neuroblastic layer made of multipotent progenitors that generate early-born cells (RGCs, horizontal, some types of 


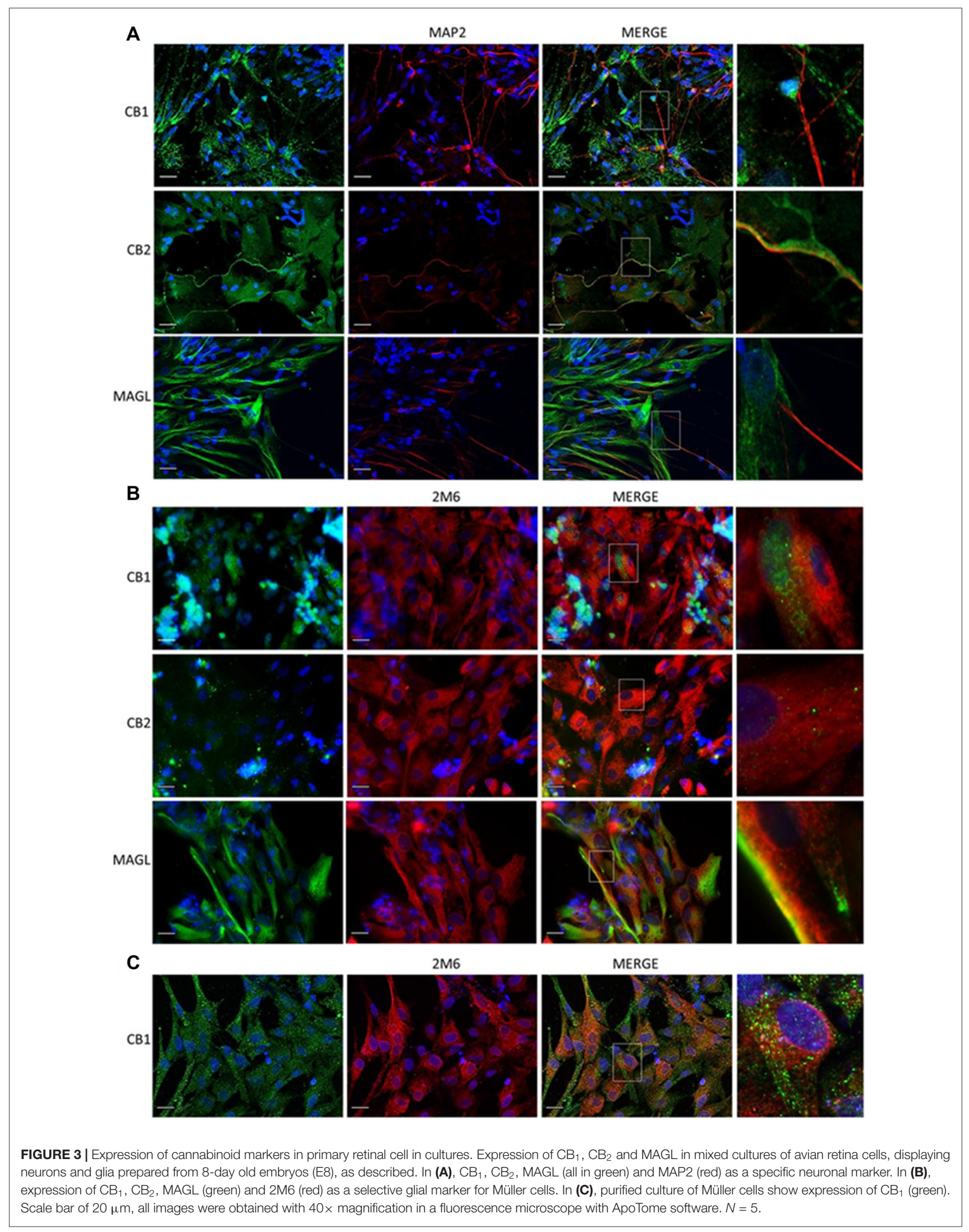



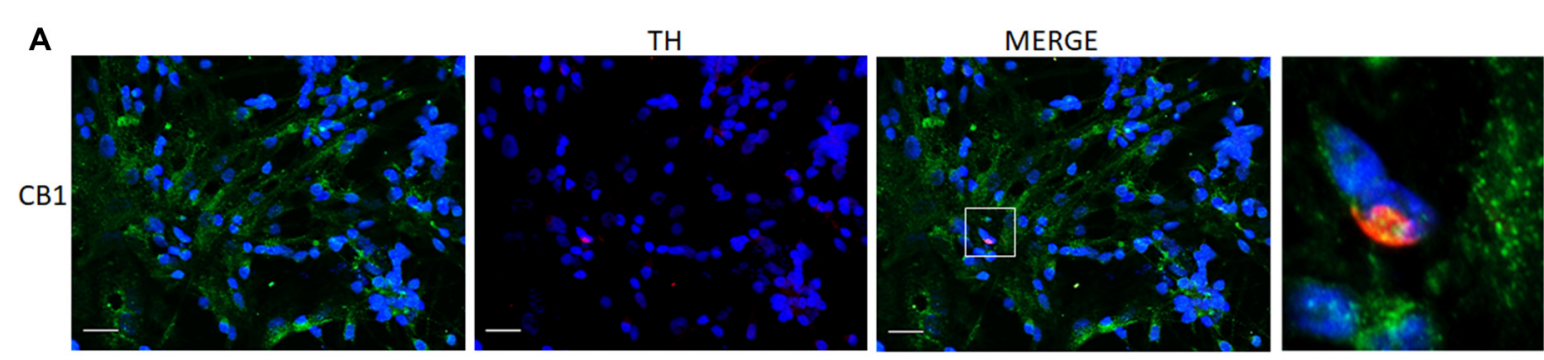

B
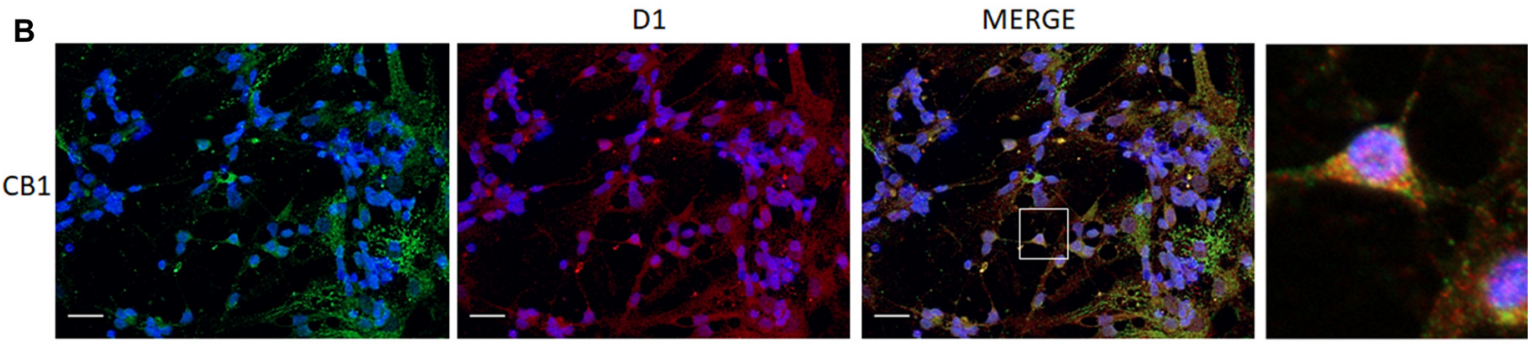

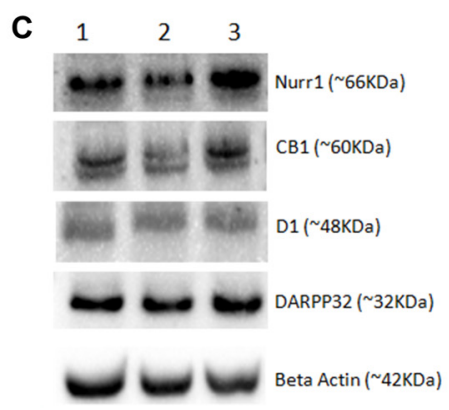

FIGURE 4 | Co-expression of selective cannabinoid and dopaminergic markers in cultured retinal cells. Expression of $\mathrm{CB}_{1}$ receptor in E8C6 cultures showing the main components of the dopaminergic system (DS). In (A), co-localization of CB $\mathrm{CB}_{1}$ (green) in TH positive neurons (red). In (B), co-localization of CB 1 (green) in cells expressing the $D_{1}$ receptor (red). In (C), western blotting analyses confirm the expression dopaminergic markers (Nurr1 and Darpp32) and $D_{1}$ receptor, in addition to $\mathrm{CB}_{1}$ expression, $\beta$ Actin is shown as the loading control (lanes represent triplicate assay as shown for $1,2,3$ ). Scale bar of $20 \mu \mathrm{m}$, all images were obtained with $40 \mathrm{X}$ magnification in a fluorescence microscope with ApoTome software. $N=3$ for each analysis.

amacrines and cones). Around E14, late-born progenitors give rise to bipolar, rods and Müller glia, so the precise number and proportion of cells into different layers form a fully mature retina (Martins and Pearson, 2008). Since $\mathrm{CB}_{1}$ (Xapelli et al., 2013) and $\mathrm{CB}_{2}$ (Bravo-Ferrer et al., 2017) receptors are correlated with proliferation and/or neurogenesis in the central nervous system, their presence early in the embryonic avian retina could modulate the generation of retinal cells. Moreover, activation of these receptors at early stages suggests that the retinal circuitry might be altered (morphologically) or in terms of function (CBs inhibit the release of GABA and aspartate (Kubrusly et al., 2018), and decrease cAMP levels, as shown in Figure 5. This could possibly reflect in changes during synapse remodeling during retinal development.

The main endocannabinoids are AEA and 2-AG, described in the retina of several vertebrates along with the main enzymes that degrade them (Schwitzer et al., 2016). MAGL, one of these enzymes, is present in rat retinal layers mainly in amacrine and Müller cells (Cécyre et al., 2014). We found that, in the avian retina, MAGL is expressed beginning at E9 and up to post-hatched PE7, where it is detected in all the five retinal layers, mostly in IPL and GCL (Figure 1E). Our data provide that MAGL is located primarily in the glial compartment as the enzyme is co-localized with 2M6 (Figure 3B, lower panel), at least in vitro. As glial cells are the last to be generated in the retina (Martins and Pearson, 2008), perhaps this explains the appearance of labeling at E9. We still cannot affirm how the developmental profile of $\mathrm{CB}_{1}, \mathrm{CB}_{2}, \mathrm{MAGL}$ and endocannabinoids match the interactions between different retinal neurons and Müller glia. However, data on Figure 5 suggest an important interplay between receptors that decrease the levels of $\mathrm{CAMP}\left(\mathrm{CB}_{1}\right.$ and $\left.\mathrm{CB}_{2}\right)$ and those that increase cAMP levels (dopamine, adenosine or PACAP) during retina differentiation.

In addition, $\mathrm{CB}$ receptor activation decreases the number of glial cells that increased $\mathrm{Ca}^{2+}$ evoked by ATP, and inhibited $\left[{ }^{3} \mathrm{H}\right]-\mathrm{GABA}$ release induced by $\mathrm{KCl}$ or L-Aspartate (Kubrusly et al., 2018). The first part of the retina that differentiates is the central part and RGCs are the first to emerge. Synaptogenesis peak in the avian retina around E14, and it is known to have 


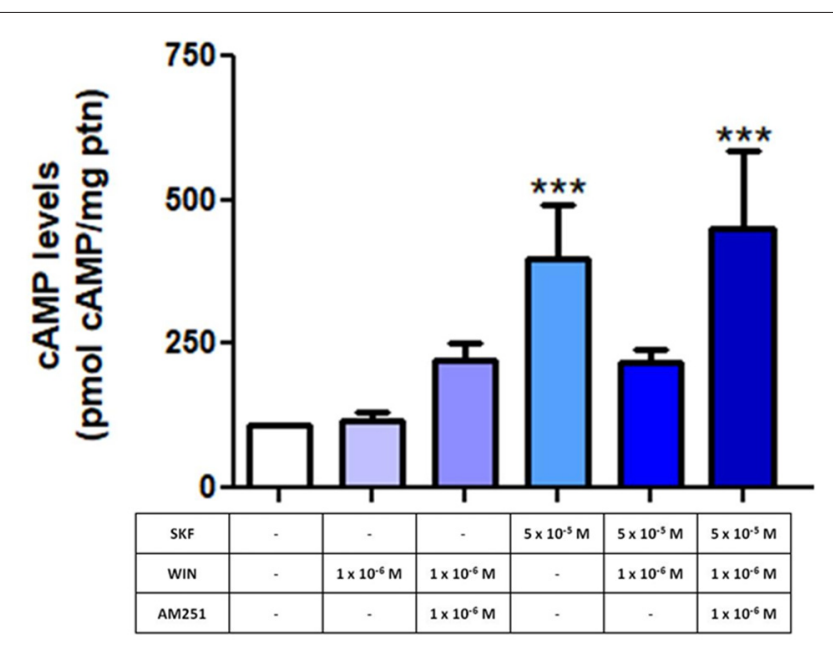

FIGURE 5 | Endocannabinoid system (ECS) modulates the function of dopamine-induced increase in cyclic AMP (CAMP) levels. E8C6 retinal mixed cell culture was subjected to CAMP quantification analysis, as described. When the selective $D_{1}$ receptor agonist, SKF38393 (SKF) at $5 \times 10^{-5} \mathrm{M}$ was used, CAMP levels increased significantly. When the culture was treated with WIN after SKF stimulation, the SKF-induced increase in cAMP levels was lost. However, in cultures pretreated with $\mathrm{AM}_{2} 51$, a selective $\mathrm{CB}_{1}$ antagonist, CAMP levels were increased (AM251 + SKF + WIN), similar to SKF-only application. AM251 was added 15 min before SKF and WIN, which were added for $30 \mathrm{~min}$, all at $37^{\circ} \mathrm{C} .{ }^{* * *}<0.001 . N=6$ for each analysis.

two main axis: glutamatergic in the vertical axis (photoreceptors, bipolar and the RGCs) and GABAergic in the horizontal axis (horizontal and amacrine; Barnstable, 1993). Moreover, Müller glia is an active compartment that shapes the circuitry (de Melo Reis et al., 2008). The ECS seems to be a powerful regulator of the efficacy of retinal circuitry.

The retina presents the main neurotransmitters found in the brain such as glutamate (Connaughton, 1995), GABA (Bringmann et al., 2009) and dopamine (Reis et al., 2007). A direct action of the ECS on retinal transmitter release and in general retinal physiology has been described in different vertebrate retinas mainly in retinal bipolar cells (Straiker et al., 1999). Interestingly, dopamine and noradrenaline release is inhibited by $\mathrm{CB}_{1}$ activation in perfused guinea-pig retina (Schwitzer et al., 2016). In the developing vertebrate retina, the DS is one of the first phenotypes to appear mainly in amacrine and interplexiform cells (Reis et al., 2007). Here, we first evaluated the emergence of $\mathrm{CB}_{1}$ and $\mathrm{TH}$ co-expression in PE7 avian retina. We observed that $\mathrm{CB}_{1}$ is co-localized with dopaminergic neurons (Figure 2) present in the IPL. $\mathrm{CB}_{1}$ is also localized in neighboring cells in IPL and also GCL, suggesting a more complex role in retina signaling. It is likely that $\mathrm{CB}_{1}$ positive cells are responsive for the dopamine released by $\mathrm{TH}$ amacrine cells and vice versa. Bosier et al. (2007) showed an important relationship between the ECS and DS using a murine neurospheres model, where $\mathrm{CB}_{1}$ agonists promoted a reduction in $\mathrm{TH}$ expression.

It is known since the 70s that dopamine increases cAMP levels in the chick retina and in mixed cultures of embryonic chick retina cells (de Mello, 1978). Since it is described that $\mathrm{CB}_{1}$ expression occurs in retinal cells in response to dopaminergic stimuli (Fan and Yazulla, 2005), we investigated the correlation between ECS and the DS. Primary cell cultures of mixed neurons and Müller glia express $\mathrm{CB}_{1}$ and $\mathrm{CB}_{2}$ receptors as well as MAGL enzyme. $\mathrm{CB}_{1}$ is predominantly in cell bodies while $\mathrm{CB}_{2}$ is found mainly in neuronal processes. On the other hand, MAGL is mainly located in Müller cells.

In order to evaluate a functional correlation between $\mathrm{CB}_{1}$ and $\mathrm{D}_{1}$ receptors, a mixed neuron-glia culture was used at E8C6, a stage where most of dopaminergic proteins are expressed. The $\mathrm{D}_{1}$ receptor agonist SKF38393 promotes a significant increase in cAMP accumulation in retina cells (Castro et al., 1999). In order to test the effect of the ECS on this $\mathrm{D}_{1}$-mediated effect, we added $A M 251, \mathrm{CB}_{1}$ receptor selective antagonist, and WIN 55, 212-2 (WIN), a non-selective cannabinoid $\mathrm{CB}_{1} / \mathrm{CB}_{2}$ agonist. Our results show that WIN decreases CAMP accumulation induced by SKF, and this response is blocked when AM251 was used as a pretreatment. Additionally, WIN did not change cAMP accumulation promoted by forskolin (not shown), a general adenylyl cyclase activator, suggesting that WIN is selectively acting on dopaminergic receptor level. Therefore, we provide evidence here that $C B_{1}$ receptor can modulate the response of $D_{1}$ receptor activation through CAMP accumulation. We conclude that the endocannabinoid and the DS interact in retinal cells.

Emergence of the ECS $\left(\mathrm{CB}_{1} / \mathrm{CB}_{2}\right.$ receptors), endocannabinoids and enzymes during embryonic retinal development might influence dopaminergic communication that seems to use two separated systems during development. One operates in early stages of retina formation, and the other, later in development. No $\mathrm{TH}$ is detected in the tissue between E5 and E10/12. However, E5 retinas display several cells (neuroblasts) clearly labeled for L-Dopa decarboxylase (DDC; da Silva et al., 2009). At this stage, or even before, the presumptive neuroretina is already associated with the pigmented epithelium, characterized by the presence of melanin. Melanin, as dopamine, use as precursor L-Dopa that in the epithelium comes from tyrosinase activity. Our group has shown that conditioned media from the pigmented epithelium of embryonic eyes fed to embryonic retina tissue prior to TH expression, is capable, of synthesizing dopamine (Kubrusly et al., 2003). This activates cAMP formation prior to TH expression. Therefore, based on the findings that $\mathrm{D}_{1}$ (increasing $\mathrm{cAMP}$ ) or $\mathrm{D}_{2}$ receptors activation (decreasing cAMP levels) in embryonic avian retina can modify the dynamics of neurites outgrowth, interference with these systems via $\mathrm{CBs}$ might influence dopaminergic circuitry. $\mathrm{D}_{1}$ and $\mathrm{CB}_{1}$ have been shown to exhibit antagonistic effects in goldfish bipolar retinal cells, as $\mathrm{D}_{1}$ activation increases cAMP level, while $\mathrm{CB}_{1}$ (WIN) reduces the concentration of cAMP (Fan and Yazulla, 2005). Our data strengthen this point using avian retinal cells to assess the interaction between the endocannabinoid and DSs.

A recent article has revealed in a pioneer way the presence of both cannabinoid receptors $\left(\mathrm{CB}_{1 \mathrm{R}}\right.$ and $\mathrm{CB}_{2 \mathrm{R}}$, the synthesizing and degrading enzymes in mice, shrews and monkey retinae (Bouskila et al., 2016). These data, added to ours in chicks (and many others) suggest a strong conservation of the ECS 
in the retinal tissue in vertebrates. This opens a possibility to create strategies to ameliorate vision problems with cannabinoid modulators. A recent article has shown that activation of $\mathrm{CB}_{2}$ receptors with a selective agonist (JWH-133) increases inflammation in human retinal pigment epithelium, decreasing cellular viability through release of pro-inflammatory cytokines and might be a central element in avoiding vision problems (Hytti et al., 2017). Both neuronal and glial $\mathrm{CB}_{1}$ and $\mathrm{CB}_{2}$ receptors might have an important role in retinal development through modulation of intracellular pathways (Kubrusly et al., 2018). Indeed, $2-A G$ is found in early retinal development together with DAGL $\alpha, 2-A G$ degrading enzyme), while MAGL, develops later (Cécyre et al., 2014). FAAH, (AEA, degrading enzyme) emerges transiently at postnatal day 1 in ganglion and cholinergic amacrine cells (Zabouri et al., 2011b).

Moreover, we show that endocannabinoids may act on the developing CNS (here exemplified by the retina), possibly influencing developmental characteristics of CNS systems such as plasticity during synapses formation (Fleming et al., 2013). We also call attention to the possibility that cannabinoid consumption might have a dramatic effect in the developing CNS.

\section{REFERENCES}

Barnstable, C. J. (1993). Glutamate and GABA in retinal circuitry. Curr. Opin. Neurobiol. 3, 520-525. doi: 10.1016/0959-4388(93)90050-9

Bouskila, J., Javadi, P., Casanova, C., Ptito, M., and Bouchard, J. F. (2013). Muller cells express the cannabinoid CB2 receptor in the vervet monkey retina. J. Comp. Neurol. 521, 2399-2415. doi: 10.1002/cne.23333

Bouskila, J., Javadi, P., Elkrief, L., Casanova, C., Bouchard, J. F., and Ptito, M. (2016). A comparative analysis of the endocannabinoid system in the retina of mice, tree shrews, and monkeys. Neural Plast. 2016:3127658. doi: 10.1155/2016/3127658

Bosier, B., Tilleux, S., Najimi, M., Lambert, D. M., and Hermans, E. (2007). Agonist selective modulation of tyrosine hydroxylase expression by cannabinoid ligands in a murine neuroblastoma cell line. J. Neurochem. 102, 1996-2007. doi: 10.1111/j.1471-4159.2007.04679.x

Bravo-Ferrer, I., Cuartero, M. I., Zarruk, J. G., Pradillo, J. M., Hurtado, O., Romera, V. G., et al. (2017). Cannabinoid type-2 receptor drives neurogenesis and improves functional outcome after stroke. Stroke 48, 204-212. doi: 10.1161/STROKEAHA.116.014793

Bringmann, A., Pannicke, T., Biedermann, B., Francke, M., Iandiev, I., Grosche, J., et al. (2009). Role of retinal glial cells in neurotransmitter uptake and metabolism. Neurochem. Int. 54, 143-160. doi: 10.1016/j.neuint.2008.10.014

Calaza Kda, C., and Gardino, P. F. (2010). Neurochemical phenotype and birthdating of specific cell populations in the chick retina. An. Acad. Bras. Cienc. 82, 595-608. doi: 10.1590/s0001-37652010000300007

Castro, N. G., de Mello, M. C., de Mello, F. G., and Aracava, Y. (1999). Direct inhibition of the N-methyl-D-aspartate receptor channel by dopamine and (+)SKF38393. Br. J. Pharmacol. 126, 1847-1855. doi: 10.1038/sj.bjp.0702479

Cécyre, B., Monette, M., Beudjekian, L., Casanova, C., and Bouchard, J. F. (2014). Localization of diacylglycerol lipase $\alpha$ and monoacylglycerol lipase during postnatal development of the rat retina. Front. Neuroanat. 8:150. doi: 10.3389/fnana.2014.00150

Chanda, P. K., Gao, Y., Mark, L., Btesh, J., Strassle, B. W., Lu, P., et al. (2010). Monoacylglycerol lipase activity is a critical modulator of the tone and integrity of the endocannabinoid system. Mol. Pharmacol. 78, 996-1003. doi: 10.1124/mol.110.068304

Connaughton, V. (1995). "Glutamate and glutamate receptors in the vertebrate retina," in Webvision: The Organization of the Retina and Visual System, eds H. Kolb, E. Fernandez and R. Nelson (Salt Lake City, UT: University of Utah Health Sciences Center).

\section{AUTHOR CONTRIBUTIONS}

LSS and RCCK: conception and design, provision of study material, collection and assembly of data, data analysis and interpretation, manuscript writing and final approval of manuscript. YPC, PPT, VTR-R, ME-L and PFG: collection and assembly of data, data analysis and interpretation. RP-C, FGM and RAMR: conception and design, provision of study material, assembly of data, data analysis and interpretation, manuscript writing, final approval of manuscript, financial support and administrative support.

\section{ACKNOWLEDGMENTS}

Grants from Fundação Carlos Chagas Filho de Amparo à Pesquisa do Estado do Rio de Janeiro (FAPERJ), Conselho Nacional de Desenvolvimento Científico e Tecnológico (CNPq), Instituto Nacional de Ciência e Tecnologia de Neurociência Translacional (INCT-INNT) and Coordenação de Aperfeiçoamento de Pessoal de Nível Superior (CAPES) supported this work. We are indebted to the technical support of Luciano C. Ferreira and Aurizete Bizerra.

Cottone, E., Pomatto, V., and Bovolin, P. (2013). Role of the endocannabinoid system in the central regulation of nonmammalian vertebrate reproduction. Int. J. Endocrinol. 2013:941237. doi: 10.1155/2013/941237

da Silva, R. T., Hokoc, J. N., de Mello, F. G., and Gardino, P. F. (2009). Differential immunodetection of L-DOPA decarboxylase and tyrosine hydroxylase in the vertebrate retina. Int. J. Dev. Neurosci. 27, 469-476. doi: 10.1016/j.ijdevneu. 2009.05.003

de Mello, F. G. (1978). The ontogeny of dopamine-dependent increase of adenosine $3^{\prime}, 5^{\prime}$-cyclic monophosphate in the chick retina. J. Neurochem. 31 , 1049-1053. doi: 10.1111/j.1471-4159.1978.tb00146.x

de Melo Reis, R. A., Ventura, A. L., Schitine, C. S., de Mello, M. C., and de Mello, F. G. (2008). Muller glia as an active compartment modulating nervous activity in the vertebrate retina: neurotransmitters and trophic factors. Neurochem. Res. 33, 1466-1474. doi: 10.1007/s11064-008-9604-1

Fan, S. F., and Yazulla, S. (2005). Reciprocal inhibition of voltage-gated potassium currents $\left(I_{K(V)}\right)$ by activation of cannabinoid $\mathrm{CB}_{1}$ and dopamine $\mathrm{D}_{1}$ receptors in ON bipolar cells of goldfish retina. Vis. Neurosci. 22, 55-63. doi: 10.1017/s0952523805221089

Fleming, R. L., Silveira, M. S., Santos, L. E., Henze, I. P., Gardino, P. F., de Mello, M. C., et al. (2013). Pituitary adenylyl cyclase-activating polypeptide receptor re-sensitization induces plastic changes in the dopaminergic phenotype in the mature avian retina. J. Neurochem. 124, 621-631. doi: $10.1111 /$ jnc. 12121

Gardino, P. F., dos Santos, R. M., and Hokoç, J. N. (1993). Histogenesis and topographical distribution of tyrosine hydroxylase immunoreactive amacrine cells in the developing chick retina. Dev. Brain Res. 72, 226-236. doi: 10.1016/0165-3806(93)90187-f

Howlett, A. C. (2002). The cannabinoid receptors. Prostaglandins Other Lipid Mediat. 68-69, 619-631. doi: 10.1016/S0090-6980(02)00060-6

Hytti, M., Andjelic, S., Josifovska, N., Piippo, N., Korhonen, E., Hawlina, M., et al. (2017). CB2 receptor activation causes an ERK1/2-dependent inflammatory response in human RPE cells. Sci. Rep. 7:16169. doi: 10.1038/s41598-01716524-w

Katona, I., and Freund, T. F. (2008). Endocannabinoid signaling as a synaptic circuit breaker in neurological disease. Nat. Med. 14, 923-930. doi: 10.1038/nm. f.1869

Kubrusly, R. C. C., da Cunha, M. C., Reis, R. A., Soares, H., Ventura, A. L., Kurtenbach, E., et al. (2005). Expression of functional receptors and transmitter enzymes in cultured Muller cells. Brain Res. 1038, 141-149. doi: 10.1016/j. brainres.2005.01.031 
Kubrusly, R. C. C., Guimarães, M. Z., Vieira, A. P., Hokoç, J. N., Casarini, D. E., de Mello, M. C., et al. (2003). L-DOPA supply to the neuro retina activates dopaminergic communication at the early stages of embryonic development. J. Neurochem. 86, 45-54. doi: 10.1046/j.1471-4159.2003.01813.x

Kubrusly, R. C. C., Günter, A., Sampaio, L., Martins, R. S., Schitine, C. S., Trindade, P., et al. (2018). Neuro-glial cannabinoid receptors modulate signaling in the embryonic avian retina. Neurochem. Int. 112, 27-37. doi: 10.1016/j.neuint.2017.10.016

Laemmli, U. K. (1970). Cleavage of structural proteins during the assembly of the head of bacteriophage T4. Nature 227, 680-685. doi: 10.1038/227680a0

Leonelli, M., Britto, L. R., Chaves, G. P., and Torrao, A. S. (2005). Developmental expression of cannabinoid receptors in the chick retinotectal system. Dev. Brain Res. 156, 176-182. doi: 10.1016/j.devbrainres.2005.02.009

López, E. M., Tagliaferro, P., Onaivi, E. S., and López-Costa, J. J. (2011). Distribution of CB2 cannabinoid receptor in adult rat retina. Synapse 65, 388-392. doi: 10.1002/syn.20856

Lowry, O. H., Rosebrough, N. J., Farr, A. L., and Randall, R. J. (1951). Protein measurement with the Folin phenol reagent. J. Biol. Chem. 193, 265-275.

Martins, R. A., and Pearson, R. A. (2008). Control of cell proliferation by neurotransmitters in the developing vertebrate retina. Brain Res. 1192, 37-60. doi: 10.1016/j.brainres.2007.04.076

Masland, R. H. (2012). The neuronal organization of the retina. Neuron 76, 266-280. doi: 10.1016/j.neuron.2012.10.002

Paes de Carvalho, R., and de Mello, F. G. (1982). Adenosine-elicited accumulation of adenosine $3^{\prime}, 5^{\prime}$-cyclic monophosphate in the chick embryo retina. J. Neurochem. 38, 493-500. doi: 10.1111/j.1471-4159.1982.tb08655.x

Prada, C., Puga, J., Pérez-Méndez, L., López, R., and Ramírez, G. (1991). Spatial and temporal patterns of neurogenesis in the chick retina. Eur. J. Neurosci. 3:1187. doi: 10.1111/j.1460-9568.1991.tb00843.x

Reis, R. A., Ventura, A. L., Kubrusly, R. C., de Mello, M. C., and de Mello, F. G. (2007). Dopaminergic signaling in the developing retina. Brain Res. Rev. 54, 181-188. doi: 10.1016/j.brainresrev.2007.01.001

Schlicker, E., Timm, J., and Göthert, M. (1996). Cannabinoid receptor-mediated inhibition of dopamine release in the retina. Naunyn Schmiedebergs Arch. Pharmacol. 354, 791-795. doi: 10.1007/bf00166907
Schlosshauer, B., Grauer, D., Dütting, D., and Vanselow, J. (1991). Expression of a novel Müller glia specific antigen during development and after optic nerve lesion. Development 111, 789-799.

Schwitzer, T., Schwan, R., Angioi-Duprez, K., Giersch, A., and Laprevote, V. (2016). The endocannabinoid system in the retina: from physiology to practical and therapeutic applications. Neural Plast. 2016:2916732. doi: $10.1155 / 2016 / 2916732$

Straiker, A., Stella, N., Piomelli, D., Mackie, K., Karten, H. J., and Maguire, G. (1999). Cannabinoid CB1 receptors and ligands in vertebrate retina: localization and function of an endogenous signaling system. Proc. Natl. Acad. Sci. U S A 96, 14565-14570. doi: 10.1073/pnas.96.25. 14565

Xapelli, S., Agasse, F., Sardà-Arroyo, L., Bernardino, L., Santos, T., Ribeiro, F. F., et al. (2013). Activation of type 1 cannabinoid receptor (CB1R) promotes neurogenesis in murine subventricular zone cell cultures. PLoS One 8:e63529. doi: 10.1371/journal.pone.0063529

Zabouri, N., Bouchard, J. F., and Casanova, C. (2011a). Cannabinoid receptor type 1 expression during postnatal development of the rat retina. J. Comp. Neurol. 519, 1258-1280. doi: 10.1002/cne.22534

Zabouri, N., Ptito, M., Casanova, C., and Bouchard, J. F. (2011b). Fatty acid amide hydrolase expression during retinal postnatal development in rats. Neuroscience 195, 145-165. doi: 10.1016/j.neuroscience.2011.08.008

Conflict of Interest Statement: The authors declare that the research was conducted in the absence of any commercial or financial relationships that could be construed as a potential conflict of interest.

Copyright (c) 2018 da Silva Sampaio, Kubrusly, Colli, Trindade, Ribeiro-Resende, Einicker-Lamas, Paes-de-Carvalho, Gardino, de Mello and De Melo Reis. This is an open-access article distributed under the terms of the Creative Commons Attribution License (CC BY). The use, distribution or reproduction in other forums is permitted, provided the original author(s) and the copyright owner are credited and that the original publication in this journal is cited, in accordance with accepted academic practice. No use, distribution or reproduction is permitted which does not comply with these terms. 